\title{
SOBRE LOS QUE NO SON, AUNQUE SEAN. ÉXITO COMO EXCLUSIÓN DE JÓVENES EMPOBRECIDOS EN CONTEXTOS CAPITALISTAS
}

\author{
Claudio DuARTE QuAPPER* \\ Los nadie: los hijos de nadie, los dueños de nada. \\ corriendo la liebre, muriendo la vida, jodidos, rejodidos: \\ Los nadie: los ninguno, los ninguneados, \\ que no son, aunque sean. \\ EDUARDO GALEANO
}

\begin{abstract}
RESUMEN
En la sociedad chilena actual, conseguir éxito se transforma en un objetivo vital en que la sobrevivencia aparece como clave para esa meta. Los efectos que ello está generando en las poblaciones jóvenes de sectores empobrecidos es el tema que se aborda en el presente artículo. El consumo opulento, estimulado desde las agencias de promoción de dicho proceso de intercambio, aparece como el proceso de mayor incidencia en la búsqueda de obtener el logro exigido-deseado; desde él se conjugan otros dos procesos en los mundos juveniles: la inserción laboral eficiente, en que se evita cualquier cuestionamiento sobre las condiciones laborales y se centra en la valoración que ese acceso tiene en tanto otorga recursos para entrar al circuito del consumo opulento, y la modernización tecnológica, como proceso de acceso, uso y valoración de las tecnologías, en especial las comunicacionales, como instrumento para conseguir el prestigio que lo modernizado otorga en nuestras sociedades. Sin embargo, los más empobrecidos van quedando fuera de estos procesos por la alta exclusión que viven, por lo que, para evitar esa condición, generan estrategias que les permitan sobrevivir y, en menor medida, resistir a quedar fuera de la fiesta del éxito.
\end{abstract}

PALABRAS CLAVE: ÉXITO, JÓVENES DE SECTORES EMPOBRECIDOS, CONSUMO OPULENTO, INSERCIÓN LABORAL EFICIENTE, MODERNIZACIÓN TECNOLÓGICA, ESTRATEGIAS DE SOBREVIVENCIA

* Sociólogo y educador popular. Académico del Departamento de Sociología de la Universidad de Chile, coordinador del Núcleo de Investigaciones en Juventudes del Departamento de Sociología. E-Mail: cduarte@uchile.cl. 


\title{
SOBRE OS QUE NÃO SÃO, AINDA QUE SEJAM. ÊXITO COMO EXCLUSÃO DE JOVENS EMPOBRECIDOS EM CONTEXTOS CAPITALISTAS
}

\begin{abstract}
RESUMO
Na sociedade chilena atual, o êxito torna-se objetivo vital, no qual a sobrevivência surge como chave para esta meta. O presente artigo analisa os efeitos deste fenômeno nas populações jovens de setores empobrecidos. O consumo opulento, estimulado pelas agências de promoção do mencionado processo de transformação, surge como o fator de maior incidência na busca do sucesso exigido/desejado; a partir dele, juntam-se dois outros processos no mundo juvenil: a inserção trabalhista eficiente, alheia a qualquer questionamento sobre as condições de trabalho, valorizando o acesso como meio para a entrada no circuito do consumo opulento, e a modernização tecnológica, no acesso, uso e valorização das tecnologias, em especial as tecnologias de comunicação, como instrumento para obtenção do prestígio que o modernizado confere em nossas sociedades. Contudo, os mais empobrecidos ficam fora desses processos pelo alto nível de exclusão que experimentam, motivo pelo qual criam estratégias que lhes permitam sobreviver e, em menor escala, resistir a permanecerem fora na festa do êxito.
\end{abstract}

PALAVRAS-CHAVE: ÊXITO, JOVENS DE SETORES EMPOBRECIDOS, CONSUMO OPULENTO, INSERÇÃO TRABALHISTA EFICIENTE, MODERNIZAÇÃO TECNOLÓGICA, ESTRATÉGIAS DE SOBREVIVÊNCIA

\section{REGARDING THOSE WHO ARE NOT, ALTHOUGH THEY ARE. SUCCESS AS YOUTH EXCLUDED BY POVERTY IN CAPITALIST CONTEXTS}

\begin{abstract}
In present day Chilean society, to obtain success is transoformed into a vital objective in the fact that survival is a key element in reaching this goal. The effects that this is generating en the youth population in impoverished sectors is a subject that we approach in this article. The opulent consumption, stimulated by promotion agencies within this process of interchange, appears as the process of greater incidence in the search to obtain or acheive the demand-wished profit; from here other it is possible to conjugate another two processes in the world of youth: efficient labor insertion, in which any questioning regarding the labor conditions is avoided, and it concentrates in the valuation that access has in as much as grants resources to enter the circuit of the opulent consumption and technological modernization, as a process of access, use and valuation of the technologies, especially the communicational ones, such as instruments to secure the prestige that the modernization grants in our societies. Nevertheless, it is the poorer ones whom are being left outside these processes by the high exclusion that they experience, which is why, to avoid that condition, they generate strategies that allow them to survive and, to a lesser extent, resist being an outsider in the celebration of success.
\end{abstract}

KEY WORDS: SUCCESS, YOUTH OF IMPOVERISHED SECTORS, OPULENT CONSUMPTION, EFFICIENT LABOR INSERTION, TECHNOLOGICAL MODERNIZATION, SURVIVAL STRATEGIES 


\section{ENTRANDO AL TEXTO}

LA CONSTRUCCIÓN DE IDENTIDADES es un tema de antigua data en las preocupaciones de las ciencias sociales. Desde diversas epistemologías se generan acercamientos a este campo de lo social que, según se van desplegando y consolidando cambios en las sociedades y culturas, se renuevan los debates y aportes en torno a él (Goffman, 2006; Larraín, 1996).

En la actualidad, uno de los abordajes a las identidades sociales tiene relación con las incidencias que las prácticas de consumo de los individuos generan en su conformación. Diversos autores han estudiado con detalle los modos en que ocurre la acción de consumir, los imaginarios generados en torno a ella, las relaciones sociales que se despliegan en su verificación, los efectos que tiene en la autopercepción de los individuos, entre otros ejes de análisis (Moulian, 1997; Moulian, 1999; García Canclini, 1990; Bauman, 1999). En estos autores, sus análisis consideran como telón de fondo, las transformaciones estructurales actualmente en proceso que están vinculadas a esta acción y noción de consumir en nuestras sociedades. De esta manera, el presente texto aborda el estudio de dichos fenómenos en el marco de sociedades capitalistas, dependientes y empobrecidas como las latinoamericanas y, en particular, la chilena (Gallardo, 2006).

Lo anterior ha sido observado con agudeza, respecto de la sociedad chilena, por Tomás Moulian en los textos ya citados. Dicho planteamiento, cruzado con mis experiencias de intervención e investigación con poblaciones jóvenes empobrecidas y su análisis crítico, son la base de la discusión que realizo en este ensayo.

Moulian elabora su reflexión para la sociedad como conjunto, mi intención en este texto es focalizar la mirada sobre una parte de la población: las y los jóvenes de sectores empobrecidos, como un ejercicio epistemológico de ajuste del foco para mejor conocer realidades específicas. Sin embargo, pongo sobre aviso a quien lee este texto, que no se trata de una concepción autonomizadora de dicha población respecto del conjunto social, pretensión que nos haría caer en una suerte de juvenilización del análisis. Nuestra exigencia en este análisis, es dar cuenta de un grupo social específico concibiéndole permanentemente en vínculo y relación — por ausencia o presencia de elloscon el resto de grupos y actores sociales.

Recojo de Moulian uno de sus planteamientos centrales en orden a que el consumo, especialmente el que se genera amparado en la modalidad crediticia, constituye hoy una forma de integración en los 
países latinoamericanos en que se consolida el nuevo orden neoliberal. Partiendo de esa premisa, y para no caer en la pretensión de que esa vía cumple de buena manera su tarea y, por lo tanto, su estímulo podría ser parte incluso de la política pública, ${ }^{1}$ es necesario debatir los efectos que el no acceso a ese consumo y la exclusión o precarización del mismo, produce en las y los jóvenes de sectores empobrecidos, pero no tanto en su dimensión de integración como en la construcción de ciertas identidades. Al decir no acceso, me refiero a que la acción de consumir y los procesos concomitantes, no se dan necesariamente en los términos esperados desde quienes administran y alimentan dicho orden.

No existen estadísticas finas respecto de esta población joven, en torno a qué y cuánto consumen, por lo que constituye una zona gris para la investigación actual. Sin embargo, los estudios muestran que son altos los niveles de endeudamiento de esas poblaciones jóvenes, en referencia al alto grado de deuda de sus familias. Esto último, dado principalmente por el acceso y compra de bienes y artículos de diverso tipo —-materiales e inmateriales— para sus hijos e hijas jóvenes (INJUV, 2007).

En continuidad con lo planteado por Moulian, se busca en este texto indagar en la construcción de identidades que hoy se generan en las y los jóvenes a través del consumo en tanto mediación y consolidación de un «sentido de vida», de una forma de ser a través del tener. Se trata de evitar la crítica moral, articulando argumentos que aporten a la historización, que develen la perversidad que existe entre consumos y subjetividades, entre tener y ser.

Lo que se critica entonces, son las relaciones sociales generadas en este proceso de consumir que, como veremos, en la medida que se torna idolátrico y se asienta en el individualismo que él mismo promueve, lleva a la pérdida de autonomía por parte de los sujetos que

1 Hace unos meses, en uno de los primeros resultados que se dieron a conocer de la V Encuesta Nacional de Juventud en Chile, se señalaba la necesidad de regular, mediante instrumentos legales, los créditos que las diversas casas comerciales y financieras le entregan a las y los jóvenes de 18 y hasta 29 años. La lógica argumentativa no era cuestionar el tratamiento sin más — homogeneizador y universalista— de las poblaciones jóvenes como potenciales consumidores, sino que explicar su altos niveles de endeudamiento a partir de la inmadurez, que según la autoridad, es característica de este sector social. 
comienzan a construir sus horizontes de realización según la pauta que la mercantilización de sus deseos y aspiraciones les impone, más desde la perspectiva de la moda y «lo que se lleva», que de aquello que podría aportarles a la realización de su autoestima y dignidad. En las poblaciones jóvenes de sectores empobrecidos estos procesos son urgentes de observar y enfrentar.

\section{SOBRE EL CONTEXTO Y LA UBICACIÓN GLOBAL DEL CONSUMO}

En un contexto de sociedades capitalistas, con economías de mercado sustentadas por ideologías neoliberales, desde un enfoque economicista, la construcción de identidad de los diversos individuos está definida por la obtención del éxito (Duarte, 1997). Ser exitoso o exitosa en estas sociedades, es el indicador que permite definir el nivel de logro y realización de cada persona. En ese sentido, podemos decir que el modelo de identidad que se ofrece-impone a los diversos grupos sociales, está definido por esta meta: tener éxito. Si bien el consumo directo juega un rol central en este proceso, en el caso de jóvenes han de considerarse otros dos modos de consumo indirecto: la producción, como forma de acceder a los recursos o medios para consumir; y, la modernización tecnológica, con exigencia de consumo para acceder a la información. Como mostraremos, los tres se interrelacionan y constituyen pilares de los actuales procesos de construcción identitaria de jóvenes en nuestras sociedades.

Cuando hablamos de poblaciones jóvenes, este parámetro del éxito se conjuga con otros aspectos de la conformación de identidades en diversos campos, desde la mirada conservadora y asimétrica que imponen las perspectivas adultocéntricas (Duarte, 1994): en lo psicosocial, se refiere a la madurez alcanzada, de acuerdo a las definiciones hechas desde el mundo adulto; en lo normativo-cultural, se refiere a la capacidad de adaptación de cada individuo a lo exigido por las diversas instituciones con que se vincula en su contexto; en lo político, que cumpla con la exigencia de la ciudadanía electoral que imponen las actuales estructuras de participación formal; entre otros aspectos. De esta forma, la interrogante por la condición de éxito alcanzado o por lograr en nuestras sociedades, como atributo y condición para ser considerado un sujeto con identidad, remite sólo a uno de los campos de la vida y no agota, de ninguna manera, la integralidad y complejidad de esas vidas. Luego, ella ha de ser leída en permanente interrelación con los otros campos. 
Una pregunta que nos ayuda a abrir este abordaje temático, desde las racionalidades que impone la economía de mercado con ideología neoliberal en nuestros países latinoamericanos y caribeños, es la siguiente: ¿qué tareas deben realizar las personas jóvenes de sectores empobrecidos para ser considerados individuos con identidad consolidada, es decir, sujetos exitosos?

Un ejercicio de historización es vital en este momento. Partimos de la tesis de que los sectores jóvenes constituyen grupos de reciente emergencia en nuestros países y que el siglo y medio de vida que tienen (Salazar y Pinto, 2003), diferenciados según clase, género y localización territorial (incluyendo la condición indígena o mestiza), nos muestra con claridad las tareas que las sociedades de la región les han impuesto en lo que, de forma naturalizada, han llamado: su proceso de inserción en la sociedad. Ya hemos debatido en otros textos que dicha inserción refiere a que se constituyan en adultos y adultas, según las modalidades que ese propio mundo adulto define en cada tiempo y contexto, como el deber ser de quienes gobiernan las sociedades y definen sus modos de relación y organización (Duarte, 2001). A ello nos referíamos antes con los diversos campos de constitución de las identidades según las exigencias de este mundo adulto, que hemos denominado adultocéntrico, en tanto configura dichas tareas de manera conservadora y asimétrica: por una parte, conservando los privilegios de que gozan en un mundo que funciona según sus designios de orden capitalista y, por otra, estrechamente vinculada, reproduciendo las lógicas de poder discriminador en las relaciones sociales, subordinando y sometiendo a los que se considera menores por su condición etárea, dependiente y no productiva en lo económico (Bourdieu, 1990).

En este proceso histórico, se ha establecido como tarea central del ser joven: prepararse para ingresar al mundo adulto. Según ello, se han definido los roles de diversas instituciones sociales: educativas, familiares, comunitarias, laborales, religiosas, militares. Todas ellas deben aportar, preparando individuos adecuados para la reproducción —conservación asimétrica - de lo construido hasta ahora. De esta forma, la escuela - en sus diversos formatos, niveles y modalidades - es la encargada principal de dotar de los conocimientos y herramientas a niños, niñas y jóvenes para que se integren de manera óptima, tanto en el mercado del consumo, como en el mercado laboral (Dávila, Ghiardo y Medrano, 2005).

Así, las identidades de estas poblaciones jóvenes aparecen mediadas o definidas como resultado de la inserción exitosa a los aparatos de consumo, producción e información. Es decir, las tareas que las 
y los jóvenes deben cumplir para ser considerados sujetos con identidad, sujetos exitosos y, por lo tanto, con visibilidad y validez social en el actual contexto, refieren a: consumir de una determinada manera, que denominamos consumo con opulencia; a insertarse en el aparato productivo en las lógicas de mercado, que llamamos producir con eficiencia; y, a modernizarse tecnológicamente, como expresión del acceso, uso y valoración de las tecnologías de punta.

Lo que a continuación mostramos es cómo, al intentar cumplir estas tres tareas, las poblaciones jóvenes de sectores empobrecidos quedan fuera de las posibilidades de integración que el consumo podría ofrecer y, al mismo tiempo, y por consecuencia de lo anterior, van profundizándose las condiciones de exclusión social a que son sometidas. Se trata de jóvenes que van quedándose con identidades ninguneadas, son tratados como sobrantes por incapaces, se les mata en vida: «los que no son, aunque sean».

\section{a) Consumir con opulencia}

Tal como señala Moulian, el consumo en contexto capitalista con ideologías neoliberales, implica el desarrollo de una práctica que permite a los individuos sentirse obteniendo metas que configuran identidad. Pero no se trata de cualquier consumo, sino de aquel que se caracteriza por ir más allá de las necesidades básicas que una persona puede definir como mínimo para su vida. Las agencias promotoras del consumo exigen alcanzar un cierto tipo y cantidad de consumo, que definen e imponen como un deber ser que, como veremos, consiste en un deber tener para ser (Bauman, 1999). Este consumo reemplaza las necesidades vitales por necesidades tipo prótesis que se instalan desde la exterioridad corporal para hacerse necesarias, reemplazables por otra del mismo tipo, pero imprescindibles para seguir viviendo.

El Mercado ofrece en este tipo de consumo, el de las prótesis, el de consumir por el placer de agregar nuevos «aparatos» a nuestros cuerpos que comienzan a ser presentados como incompletos. Lo que les falta es lo que ha sido definido como «lo último», «lo que se lleva», que si no lo poseen, se perciben como cuerpos minusválidos, en el sentido de menor valor, de cuerpos lisiados, es decir, imposibilitados de ser y hacer. Tanto arraigo logran estas promociones e imposiciones, que de no conseguirse estos aparatos se generan, y posteriormente validan, sentimientos de angustia, culpa e incumpletitud. Más adelante volveré sobre esta última idea. 
Este tipo de consumo, resulta de estrategias de seducción permanente, que las diversas agencias promotoras despliegan hacia diversos nichos de población creados de acuerdo a lo focos en los cuales desean instalar determinados productos. En el grupo social que nos interesa, un ejemplo ilustra esta situación: la existencia de un grupo denominado jóvenes adultos, que emerge como creación desde las agencias que observan el nuevo comportamiento de la educación superior en nuestros países y que ha llevado a la extensión del tiempo de permanencia en la universidad, a propósito de las lógicas de educación continua que se promueven en la última década, y del alto número de profesionales - comparado con décadas anteriores - que existen por esa masificación de la educación superior. Se suma a lo anterior, el atraso en la edad de matrimonio o la exclusión de éste como parte de los proyectos de vida, el atraso en el comienzo de la crianza, entre otros aspectos. ${ }^{2}$

Pues bien, el grupo que egresa de estas experiencias educativas es capturado —en todos los sentidos de la palabra - como un nuevo grupo social, una nueva fase de la vida, que ha de constituir identidad propia, pues tendría roles y tareas específicas de acuerdo a su nueva condición, es decir, se ha pretendido constituirlo como categoría de análisis social —análogo a niñez, juventudes, adultez, vejez, etc.Sin embargo, dicho proceso social es más complejo y de largo aliento que lo que las agencias de publicidad e incitación al consumo pueden imponer. En lo que ha quedado, es en un conjunto de ofertas, que definen dicho nicho de mercado y que están especialmente dirigidas a este grupo social: cuenta bancaria joven, auto joven, tipo de departamento (lofts), ciertas prácticas de consumo cultural, cierta moda de vestuario, entre otros aspectos.

Estamos mostrando entonces, cómo funcionan los mecanismos de mercado que crean necesidades y las imponen a grupos de este tipo, que luego terminan queriendo construir sus vidas según dichos parámetros, pues «así dicen que debemos ser». Lo aspiracional emerge más vinculado al acceso a ciertos bienes materiales e inmateriales, que otorgan un prestigio que asegura el éxito en tiempo presente, que a logros que pudieran constituir estrategias de desarrollo en el largo plazo de la vida.

2 Es relevante considerar factores de clase, género y localización territorial en este ámbito de análisis pues, según ellos, se establecen diferencias significativas en diversos grupos, aunque la tendencia mencionada es global. 
Un error teórico relevante en estos debates, es la pretensión de reducir el surgimiento del grupo social juvenil a la existencia de procesos de consumo de estos sujetos, que darían cuenta de la emergencia de culturas juveniles en el período posterior a la segunda guerra mundial. No sólo por eurocéntrico es cuestionable dicho planteamiento sino, sobre todo, porque invisibiliza y niega las condiciones estructurales que posibilitaron dichos procesos de surgimiento y que, para América Latina y El Caribe, están asociados a los cambios en el modo de producción y la emergencia de la organización capitalista de las sociedades y sus economías a largo de los siglos XIX y XX (Salazar y Pinto, 2003; Muñoz, 1999).

Distinta es la constatación de que, una vez que las poblaciones jóvenes fueron consolidándose en las sociedades de la región, las agencias de promoción de consumo les hayan dedicado especial atención y dirigido buena parte de sus seducciones para imponerles identidad, en tanto consumidores específicos de determinados tipos de bienes. Lo que ello ha generado es la constitución de ciertas modas juveniles, comprendidas estas como procesos de incitación al consumo a partir de la elaboración de determinados patrones estéticos que, al ser usados y por lo tanto consumidos, de manera inherente otorgarían condición juvenil a su portador o portadora (Marcuse, 1973; Margulis y Urresti, 1996).

Aquí se abre otro aspecto relevante que constituye la imagen como totalización de identidades: «ser lo que se lleva». Es decir, se parte de la moda como urgencia para «ser alguien», ganar en identidad en la medida que «soy lo que hay que ser». Estar fuera de este circuito es no ser nadie, es perder sentido, es no tener identidad.

En este marco es que hablamos de un consumo opulento, comprendido como aquél que se despliega como manifestación de excesos para lograr dar cuenta de estas nuevas necesidades. Son los no límites, aquéllos que se difuminan hasta volverse inexistentes, pues cuando de consumir se trata no hay imposible que neutralice el deseo generado. Es tan fuerte la incidencia del discurso que promueve este tipo de consumo, que de no lograr alcanzarlo aparece el sentimiento de no estar completos, de ser menos e incluso de ser perdedores, porque además la obtención del éxito remite a un triunfo sobre otros. La lucha ha de ser enfrentada y nada puede detener la satisfacción de esas ansias. Se trata de desear el deseo, más allá del objeto mismo (Bauman, 1999). Es la fascinación que plantea Moulian (1997).

Sin embargo, existen mecanismos de acceso a este consumo en perspectiva de conseguir éxito, que generan posibilidades e imposibi- 
lidades para ese acceso, por lo que es relevante analizarlos y debatirlos. Como parte y respuesta a esas posibilidades y su antinomia es que muchos jóvenes implementan estrategias de diversos tipos buscando sobrevivir en la lucha señalada. De ellas destacamos el endeudamiento, la marca y el robo.

i) El crédito-la deuda (de otros) como mecanismo efectivo de acceso. Tal como ha mostrado Moulian, el crédito es el mecanismo más eficaz, que el actual modo de funcionamiento de mercado ha generado, para promover el acceso al consumo de la población que no puede pagar en efectivo y debe endeudarse para conseguir los bienes promovidos como necesarios. En ese proceso las y los jóvenes de sectores empobrecidos y capas medias han de recurrir a sus padres y madres para que compren por ellos y/o para ellos. Es decir, es el endeudamiento de otros el que les permite el acceso, por lo que dependen de su capacidad de contraer deudas y de la disponibilidad para hacerlo. Es entrar en el juego, pero con el amparo de avales familiares.

En este caso es importante señalar el paulatino aumento de agencias promotoras de consumo - en especial grandes casas comerciales y financieras-, que han comenzado a constituir un nicho de financiamiento directo a estudiantes universitarios de instituciones públicas y privadas que, con sólo tener 18 años y acretidar su condición de estudiantes, les otorgan una tarjeta bancaria con un monto de dinero disponible para utilizar. «Parece un regalo» es la expresión más escuchada en estudiantes que, al parecer sin darse cuenta, caen en la trampa de la fetichización del dinero, y creen que ese monto les pertenece, es de su propiedad y pueden hacer con él lo que deseen (Hinkelammert, 1991). Al momento de pagar —incluido los intereses y mora — vendrán las dificultades.

Similar es la situación cuando compran a crédito, sin dinero efectivo, sí con dinero plástico, la tarjeta. Con ella, la sensación reportada por muchos jóvenes es «como que no estoy pagando», y claro, al no existir dinero tangible en el intercambio, se invisibiliza el valor de cambio que en dicho proceso se está produciendo. Igual que en el caso anterior, las dificultades aparecen después cuando no se puede pagar y se acumulan intereses y mora.

En ambas situaciones, un aspecto relevante en la producción de identidades es la percepción de hacerse parte de un colectivo, el de compradores-consumidores, que muchos jóvenes señalan al participar de la fiesta del consumo. «Me siento parte de...». Es la noción de la «ciudadanía credicard» planteada por Moulian (1997), que refiere al sentido colectivo que ganan quienes consumen de esta forma, que re- 
nunciando a la dimensión política de la ciudadanía se quedan en aquélla que les transforma en parte de la ciudad en tanto consumidores.

Lo anterior nos muestra un mercado asumiendo riesgos con sujetos que pueden no ser buenos clientes - no compran o no pagan-, pero es un riesgo sobre seguro, pues las condiciones de todo el proceso económico les avalan buenos resultados en esa aventura. Los mecanismos legales existentes les darán la razón ante cualquier controversia que se pueda plantear.

ii) Ser marquero como «dar la talla». Otra estrategia, reportada principalmente en los sectores más empobrecidos y en grupos de jóvenes pertenecientes a sub culturas en que la estética es un elemento vital y ella se obtiene principalmente a través de prendas de vestir, consiste en obtener —-mediante el tráfico, si es necesario — las chapas o etiquetas que indican las marcas de determinados productos.

Una vez alcanzado el sello, lo que sigue es adosarlo a una prenda de menor calidad que la indicada por la etiqueta, pero que la hace aparecer como prenda legítima. Tal es el caso de jeans, casacas, zapatillas, etc. Y diversos elementos que permiten potenciar la imagen y ganar en prestigio en el proceso de construcción de identidades.

Se trata entonces de una estrategia que podemos enunciar así: «ser, haciendo como que soy», es el rebusque a través de la pose —una postura breve, sólo instrumental-. Es como aquellos que posan usando celulares de madera, mientras conducen su automóvil simulando que conversan y lo que es peor, que se comunican; o que van al Supermercado un fin de semana y se pasean con productos caros en el carro de compras, conversando con quienes se encuentran y mostrando lo que llevan, para luego de algunas horas de liturgia necesaria, abandonar el lugar sin comprar nada, pero con el espíritu lleno del prestigio y la aprobación social ganadas en mostrarse haciendo como que es; o quienes en verano con altas temperaturas, transitan en sus vehículos con las ventanas cerradas, simulando tener aire acondicionado, pero haciendo como que sí lo tienen; o quienes pegan en las ventanas de sus automóviles o casas, adhesivos de colegios privados de barrio alto, aunque nadie de su familia estudie o haya estudiado en él, pero que les permite hacer como que sí lo hicieron alguna vez.

Es un simulacro, un amague a la realidad, es un dribbling a la imposibilidad de acceder, es tratar de ganarle la batalla a la exclusión y sentirse parte de la fiesta, es tratar de salir en la foto. Es la pose para ser alguien. 
iii) El robo como legítimo esfuerzo emprendedor. ¿Por qué roban las y los jóvenes de sectores empobrecidos en nuestros países? El discurso adultocéntrico respondería presurosamente que se trata de individuos que intrínsecamente están vinculados a la maldad, que son un riesgo, una amenaza, un problema para la sociedad. Seguidamente, desde este discurso se propondría bajar cada vez más la edad de penalización y que se aumenten las penas y castigos para ellos y ellas (Cortés, 2007).

Sin embargo, en la línea de la reflexión hasta aquí realizada, parece pertinente sugerir que una de las posibles explicaciones o factores que inciden en este fenómeno de delincuencia en poblaciones jóvenes, se genera a partir de la búsqueda de acceder y «tener aquello que dicen que hay que tener». Pero, es la búsqueda a través de estrategias que se saltan las normas y límites, que contradicen la buena crianza, que no escuchan las prédicas conciliadoras. Se trata de robar, de tomar lo ajeno como propio.

Es el camino con atajos, es la estrategia del rebusque con viveza. Esa que va más allá de lo permitido, superando el camino que asumen los débiles, quienes aceptan y se someten a los límites.

No es robar por nada, es robar para acceder, para ser parte de la fiesta, para aparecer en la fotografía del éxito, de los incluidos e integrados. Es la delincuencia que no mide consecuencias ni la posible dureza de sus métodos, sólo piensa en sus resultados inmediatos, tener con qué comprar aquello que dicen debe consumirse para ser. No es la delincuencia con valor de subcultura, ni como ajuste ante la diferencia de clases y la desigualdad, se trata de otras lógicas, pasajeras, eficaces (Cooper, 2005). Sólo es un instrumento que permite salir de la nada para aparecer. Es solo por un rato, para poder hacer como que se es alguien. No es la delincuencia como opción de vida ni como probabilidad de futuro. Es la racionalidad instrumental del medio y del fin, integradas y confundidas en lógicas de nuevo tipo. Todo sea por el éxito.

¿Qué ocurre con las y los jóvenes empobrecidos cuando logran acceder al consumo, pero no obtienen los resultados que la publicidad ofrecía? Lo que estos sujetos señalan es que la felicidad asociada al consumo, no consigue ser obtenida y a pesar de que es creciente su consumo, más tristes y dependientes se vuelven. Lo que planteamos es que son potentes las imposibilidades en las y los jóvenes a partir de su condición de empobrecidos. Acceden al consumo, pero no logran el éxito prometido y, más bien, se refuerzan sus condiciones de exclusión. 
En los cuerpos de estos jóvenes se instalan las consecuencias de estos procesos de perversión social, en que se les ofrece la felicidad, se les induce y seduce al consumo opulento como medio único para esa dicha, una vez que acceden y no logran el efecto esperado, la angustia y la autoagresión aparecen como horizonte de posibilidad.

Es un sentido compartido en el imaginario social que el genotipo de los sectores empobrecidos no se parece en nada al de las y los modelos -imágenes corporales plenas de parámetros hegemónicos para los géneros femenino y masculino- que están instalados por las agencias promotoras del consumo como estereotipos a conseguir. Pues bien, lo que muestra el habla de estos jóvenes es que por más esfuerzos que hacen, no logran parecerse a las estrellas de moda, ni a Barbie ni a Kent, además porque nuestra contextura corporal está heredada en gran medida de la mezcla entre europeo español y los pueblos originarios, cuyo resultado ni se acerca a estos prototipos impuestos principalmente desde los medios de tipo audiovisual (TV, cine, internet).

En ocasiones esta imposibilidad, agudizada por la culpa de no ser capaz, termina generando un efecto todavía más grave que consiste en la autoagresión al cuerpo. Es la angustia como resultante de la imposibilidad, ya no tanto del acceso, pues los mecanismos existen, sino por el no logro del éxito. Así, enfermedades actuales como la anorexia, bulimia, obesidad por mal nutrición, etc., pueden estar constituyendo expresiones de un malestar que recorre silenciosos los cuerpos juveniles y se instala en sus identidades derrotadas, incompletas, en definitiva: no exitosas.

De esta forma, podemos observar cómo el consumo con opulencia no logra ser satisfecho dentro de las posibilidades ofrecidasimpuestas por el mercado que incita a dicho consumo y que para lograr acceder a él, las y los jóvenes de sectores empobrecidos han de desplegar estrategias para dar la talla de lo esperado. Sin dichas estrategias la frustración es alta; aun con dichas estrategias, la sensación de incompetencia e impotencia es alta, pues ellas tienen carácter breve, pasajero e ineficaz en el largo plazo para estos jóvenes. No necesariamente se produce la inclusión feliz ofrecida en la publicidad. El éxito en clave neoliberal queda atascado en el estrecho margen de movimiento que tienen al no poseer las condiciones para el acceso. El mismo sistema de mercado que les ofrece e induce, les niega y margina de las posibilidades. 


\section{b) Producir con eficiencia}

Como ya señalamos, desde una mirada economicista en nuestras sociedades capitalistas, la condición juvenil en el amplio debate de su construcción social, aparece definida desde una de sus vertientes como integración al mercado laboral. Es decir, se la caracteriza como proceso de preparación para esa incorporación, la que al ser lograda es planteada como una meta que marcaría un ritual de pasaje al mundo adulto (Weinstein, 1994).

Ya hemos debatido en otros textos la linealidad y asimetría de este tipo de definiciones (Duarte, 2001). Sin embargo, para la discusión que ahora estamos abordando, hemos de partir de ella como una de las nociones centrales en los discursos adultocéntricos sobre identidades de poblaciones jóvenes.

Pues bien, desde pequeños, niños y niñas van recibiendo un conjunto de discursos sociales cuya preocupación central está puesta en «¿qué serás cuando grande?», apareciendo dicha proyección directamente definida por el tipo de trabajo que se ejercerá. La vocación es reducida a profesión u oficio y pierde cualquier ligazón imaginable que refiera a felicidad y despliegue de talentos e intereses, quedando sujeta a racionalidades en que priman las ganancias económicas y el éxito, por sobre otra consideración. El sistema educacional refuerza lo anterior y conjuga, junto al sistema familiar, esta obligación de prepararse para ser adulto mediante el ingreso al mundo del trabajo.

En una mirada global, vemos que las economías de mercado necesitan a las y los jóvenes como potenciales productores y, buena parte de la organización de la política pública y otras intervenciones, están pensadas en función de asegurar su ingreso adecuado al mundo laboral. Adecuado significa aquí, según los términos que el éxito plantea.

Pero, ¿qué les ofrece el mercado del trabajo a jóvenes empobrecidos, en sociedades capitalistas con economías de mercado e ideología neoliberal?

Los elementos centrales de la oferta del Mercado, en el contexto de la alta precarización (Figueroa, 2003), que nos aportan en la reflexión que estamos desarrollando, refieren a la política pública, el imaginario privado y la antipatía política.

En cuanto a la política pública, desde principios de los noventa, uno de los ejes de la oferta para jóvenes, del primer Gobierno de la Concertación, fue instalar el tema de su empleabilidad. Para ello, se realizaron esfuerzos en la dirección de su capacitación y puesta al día 
en los cambios tecnológicos crecientes en el mundo; para esa instalación se recurrió a la noción que valoraba la importancia de darle una oportunidad a las y los jóvenes y, al mismo tiempo, el llamamiento para que se constituyeran en emprendedores (Marcel, 1990; Echeverría, 1990). Este segundo aspecto se refuerza con los imaginarios privados que veremos más adelante.

En lo que refiere a la oportunidad, la política pública, hasta ahora ha consistido mayormente en la asignación de subsidios a empleadores para que financien parte de la incorporación de jóvenes en puestos de trabajo (Figueroa, 2003). Sin embargo, los programas implementados no han considerado necesariamente el aseguramiento de continuidad en el tiempo para estos trabajadores, ni las buenas condiciones laborales para su desarrollo, ambas cuestiones básicas en la propuesta hoy señalada por organismos internacionales en torno a la generación de trabajo decente (OIT, 2003).

Desde los imaginarios privados, el ser emprendedor, en coincidencia con el discurso gubernamental, aparece como el horizonte del tipo de trabajador que se necesita para que el mercado del trabajo funcione adecuadamente (Flores y Gray, 2002). Este emprendimiento se caracteriza principalmente por una acción individual, que busca mediante el esfuerzo personal, salir de situaciones de complicación para pasar a estadios de mejor condición. No aparecen en este afán de superación, lógicas colectivas ni búsquedas de felicidad en el espacio del trabajo, como experiencias de transformación de la naturaleza o como posibilidad de producciones innovativas al servicio de otros u otras. Todas esas pretensiones son señaladas como entelequias fuera de contexto e imposibilidades que no se condicen con el modelo de trabajador moderno y eficiente. Aquel que no sólo le agradece a su empleador por «darle» trabajo, sino que además procura ser eficiente, es decir, de bajo costo y generador de alta ganancia, de manera que la relación costo beneficio sea cada vez más auspiciosa a favor de quien le provee no sólo de un salario, sino de lo más importante: la posibilidad de acceder a la fiesta del consumo, al éxito prometido.

Así, la capacidad de emprendimiento aparece como un requisito fundamental para ser considerado adecuado en el mercado del trabajo. $\mathrm{O}$ lo que es lo mismo, una alta cuota de individualismo es vital para el despliegue de óptimas estrategias de sobrevivencia. A partir de este aspecto, surge el tercer elemento ya enunciado como parte de la oferta del Mercado: la antipatía política. 
Si se pretende ser un buen empleado, hay actitudes y conductas que quedan inherentemente desterradas del abanico de expresiones posibles en el espacio laboral: la manifestación de malestar por las propias condiciones laborales, la preocupación por la situación de otros u otras, la sindicalización, el ejercicio de derechos, todos aparecen como extraños e inadecuados a la experiencia laboral. Lo que se debe asegurar es la propia sobrevivencia en el espacio del trabajo y atender a los peligros que implica vincularse más allá de lo necesario.

En este marco, lo político, entendido como la toma de posición y acción ante la realidad inmediata, aparece como un peligro de exclusión del mercado laboral, si esas opciones tienden o insinúan ponerse en la dirección contraria a lo señalado por empleadores o dueños del capital económico. Entonces es mejor callar. La mejor actitud política es el silencio y el ensimismamiento, no participar y participar callando. La antipatía a la política reivindicativa, pues ella expone a la pérdida de aquello que permitirá el éxito.

Para las y los jóvenes de sectores empobrecidos que ven al mercado laboral como un espacio restrictivo para quienes se integran a él, los mecanismos de acceso o las posibilidades (imposibles), tienden a reforzar los nocivos efectos contenidos en la oferta y en su materialización. Por ello, es necesario distinguir las estrategias que se utilizan para la incorporación y la sobrevivencia. Relevamos tres en este análisis.

i) Más educación, más (im)posibilidades. La Comisión Económica para América Latina y El Caribe (CEPAL) y la Organización Iberoamericana de Juventud (OIJ) publicaron a fines de 2004 La juventud en Iberoamérica. Tendencias y urgencias. A partir de sus resultados, elaboran un conjunto de paradojas que expresarían ciertas tensiones manifiestas en las condiciones juveniles.

Una de estas paradojas refiere a que las poblaciones jóvenes tienen hoy más acceso a educación, pero menos acceso a empleo. La tensión que esta situación plantea, está en que la oferta educativa no posee la calidad esperada aunque su cobertura haya aumentado, lo que no permite a las y los jóvenes empobrecidos una inserción decente a los mercados laborales. Más bien, lo que tiende a ocurrir es que ellas y ellos, a pesar de contar con más años de estudios que las generaciones mayores en sus familias y países, tienen pocas posibilidades de insertarse en buenas condiciones en los mercados de trabajo (Duarte y Figueroa, 2005).

Se suma a lo anterior, la poca pertinencia que las especialidades estudiadas en la enseñanza media y en algunos Centros de Formación 
Técnica tienen respecto de las necesidades del mercado laboral en cada una de sus ramas. Lo anterior, lleva a que se encuentren saturadas ciertas especialidades o disciplinas que el mercado y la imagen mediática muestran como sinónimos de prosperidad económica, en desmedro de otras que son señaladas como antesala del empobrecimiento permanente.

¿Qué sentido tiene seguir estudiando, si mañana seré un cesante ilustrado? Es la interrogante que se plantean muchos jóvenes que hace rato dejaron de percibir la educación como mecanismo de movilidad social (Dávila, Ghiardo y Medrano, 2005). De esta forma, las posibilidades de alcanzar el éxito, por la vía de tener más estudios para ser alguien, está puesta en duda de manera significativa en las poblaciones jóvenes empobrecidas.

ii) Política pública de empleo para jóvenes como refuerzo de la precarización. En continuidad con lo anterior, aparece con claridad la imagen de una sociedad que se percibe avanzando hacia el crecimiento y el desarrollo, pero que va dejando tras de sí una estela de sujetos que quedan al margen de los beneficios de ese crecimiento y desarrollo. A las y los jóvenes, según la CEPAL, se les considera más aptos para el cambio productivo, pero con menos posibilidades de participar en él. Porque aunque poseen más años de estudios que sus padres, madres y abuelos/abuelas, sin embargo, de poco les sirve si los mercados del trabajo no disponen de las condiciones para una inserción y mantención digna en ellos, por lo que terminan más excluidos de dicho cambio productivo.

En nuestro país y en la región, las formas de organización del trabajo y las transformaciones de la vida económica han cambiado de forma significativa en los últimos 25 años (Martínez y León, 2001; Díaz y Martínez, 1995). Las formas de establecer las relaciones entre capital y trabajo y el tipo de empleo, especialmente, en cuanto al contenido de las competencias laborales, condiciones de trabajo y los modos de definición de los salarios, se han modificado sustancialmente. Esto ha reorganizado las formas de inserción laboral de los y las jóvenes, especialmente, si las comparamos con las de sus padres o abuelos que tuvieron la fábrica como referencia, mientras que ellos se perciben mucho más cercanos al sector servicios (Dávila, Ghiardo y Medrano, 2005).

La política pública de empleo para poblaciones jóvenes, enfrentó durante los primeros gobiernos de la Concertación, la búsqueda de su inserción mediante programas masivos de capacitación laboral, inten- 
tando pagar una deuda que la sociedad chilena tendría con sus jóvenes (Cottet y Galván, 1993). En la medida que estas iniciativas no tuvieron un impacto significativo - el desempleo en jóvenes entre 18 y 24 años, triplica en los promedios al total nacional, en las comunas más pobres lo quintuplica-, la política pública desde principios del 2000, giró hacia la lógica ya señalada de los subsidios a empleadores. Ninguna de las dos ha tenido un impacto significativo, pues la problemática que se quiere enfrentar tiene características estructurales en lo económico y adultocéntricas en lo cultural y político. Mientras se perciba a las y los jóvenes como sujetos sin experiencia, de menor valor en el mercado laboral, se seguirán aplicando políticas que expulsan y desmotivan, más que estimulan a la inserción.

Un ejemplo claro de lo anterior, es el amago de debate que se instala en nuestro país cada vez que se plantea la temática del salario mínimo. Surgen voces que plantean la necesidad de que exista un salario mínimo destinado a jóvenes menores de 24 años y que ha de ser inferior en cantidad, que el destinado al resto de la población trabajadora. El argumento principal que se esgrime, es que estos sujetos jóvenes «tienen menos necesidades» que el resto de la población mayor. Hasta donde conocemos, el capitalismo en ningún momento ha calculado los salarios de acuerdo al criterio de necesidades de quienes venden su fuerza de trabajo. Si eso fuera así, quizás nos estaríamos acercando a otras formas de organización económica, cuestión que no ocurre en este momento de la historia en nuestra región.

Lo anterior, nos muestra que sólo se trata de un argumento capitalista y adultocéntrico que, a partir del prejuicio de que los menores (niños, niñas y jóvenes) son dependientes económicamente y, por lo tanto, requieren menos recursos propios, pretende abaratar los costos a empresarios y maximizar sus ganancias. Éstos con seguridad pagan salario mínimo sólo a trabajadores de baja calificación que, como ya hemos dicho, provienen en su mayoría de los sectores más pobres.

iii) ¿Un problema de madurez o de la estructura del mercado? Siguiendo con la argumentación anterior, encontramos que las y los jóvenes de sectores empobrecidos no son vistos como eficientes, pues no poseen adecuada preparación, son poco dóciles y tienen alta tasa de movilidad ya que permanecen poco tiempo en sus lugares de trabajo. Esta alta rotación, es explicada por el discurso empresarial como inestabilidad e inmadurez "propia del ser joven», que muestra su falta de responsabilidad y carácter adolescente —que adolece, carece- - Esta explicación de orden adultocéntrica, es parte del discurso común entre 
diseñadores de política, empleadores y docentes que alistan a estos jóvenes para el empleo.

Sin embargo, esta alta rotación responde más al desagrado que provocan las malas condiciones de trabajo y a la búsqueda de mejores posibilidades por parte de las y los jóvenes, que a un desajuste intrapsíquico. En cierta medida, se transforma entonces en una práctica de rechazo a las no decentes condiciones impuestas y un modo de resistirse buscando mejorías.

Las características de flexibilidad que el mundo empresarial demanda para sí como condición fundante del actual modo de organización del empleo, termina siendo aprovechada como vía de escape temporal para estos jóvenes, en esa búsqueda de mejores condiciones. Sin embargo, esa vía es individual, no alcanza ribetes colectivos, no moviliza, funciona dentro de la lógica individualista a la que han sido arrastrados y arrinconados los sectores de trabajadores de la región. Las y los jóvenes no son ajenos a esa situación.

¿Qué ocurre con las y los jóvenes de sectores empobrecidos cuando no acceden al aparato productivo y pierden la posibilidad de ser eficientes y exitosos como demanda el mercado? La carencia de preparación adecuada, marca de forma señera a las poblaciones jóvenes empobrecidas y les ofrece un lugar de alto sometimiento en el mercado laboral o la exclusión del mismo. Otra alternativa, camino a la eficiencia, implica esforzarse en lo personal y prepararse para ocupar otro lugar, de liderazgo y mejor posicionamiento. Para ello, la profesionalización universitaria es fundamental. De ella, los sectores empobrecidos están más lejos que cerca.

A lo anterior, ha de agregarse la internalización del discurso del éxito. Un sector importante de las y los jóvenes, valoran como un logro relevante conseguir un lugar en el mercado del trabajo y, con ello, no es de extrañar que las situaciones acontecidas en este espacio social no aparezcan mencionadas como problemas relevantes entre ellos y ellas. La V Encuesta Nacional de Juventud, muestra resultados que avalan este planteamiento, en el sentido de que a pesar de señalar que trabajan en condiciones de precariedad (sin contrato, sin previsión, con estados de prueba permanentes, salarios inestables, etc.) valoran tener trabajo y ser parte del mercado del empleo (INJUV, 2007). La explicación posible, es que conseguir la inserción laboral abre la puerta para acceder al consumo ofrecido y ser parte también de ese mundo de tener para ser. 
En ese sentido entonces, la inserción laboral, lejos de aspectos de índole vocacional, asume una condición instrumental, más bien referida a la sobrevivencia y al logro de metas individuales de satisfacción inmediata. Se trata de tener con qué acceder al consumo que permite ser a través del tener. Es la posibilidad de verificar la fascinación por el consumo tomando la vía correcta, con recursos propios, crédito de por medio si es necesario, pero por la ruta esperada: fruto del esfuerzo, el éxito pauteado socialmente.

Cuando son de este tipo las explicaciones construidas, lo que conceptualizamos es la creciente naturalización de sus condiciones de trabajo. Es el modo actual de expresión de la enajenación de los sujetos en la experiencia laboral. En la medida que la preocupación está puesta en lograr acceso al consumo y por esa vía al éxito y la identidad, aquellos problemas y obstáculos que aparezcan en ese camino se transforman en el ideario neoliberal y en desafíos al esfuerzo emprendedor ya presentado. El circuito se retroalimenta. Parece sin posibilidad de escape.

De esta forma, conseguir éxito en contextos neoliberales para las y los jóvenes de sectores empobrecidos se traduce como entrar en la lógica impuesta: ser eficientes, es decir, producir altas ganancias para su empleador con un bajo costo. No aceptar dicha premisa implica arriesgarse a la exclusión, quedar fuera del baile, otra vez no salir en la foto.

\section{c) Modernizarse tecnológicamente}

Un ámbito del actual contexto capitalista, es la ampliación veloz de las tecnologías electrónicas e informáticas. La mundialización como proceso inducido y asimétrico (Gallardo, 2006), ha permitido la masificación de esta producción tecnológica, así como la consolidación de la misma, en tanto artefactos vitales para la mayor parte de los campos de nuestra vida contemporánea. En lo laboral, en la medicina, en las comunicaciones, en la educación y en otros ámbitos, ya parece impertinente pensar en su realización sin el uso de tecnología electrónica y computacional.

De esta forma, la actual expresión de la modernización aparece vinculada de forma estrecha al menos a tres premisas que homologan modernización y tecnologización: acceso, uso y valoración de esta tecnología de punta. «Ser modernizado» hoy, exige cumplir con esta triada respecto de la alta tecnología. Sin embargo, el contexto actual muestra que dicha vinculación directa se ve dificultada por condicio- 
nes que las poblaciones jóvenes viven diferenciadamente y que les posicionan de manera diversa ante estos procesos de tecnologizaciónmodernización.

Según la CEPAL y OIJ (2004) los jóvenes tienen más acceso a información, pero menos acceso al poder. Como consecuencia de lo anterior, vemos que las y los jóvenes con su mayor manejo de los sistemas tecnológicos, tienen mayor acceso a información y a diferencia de las generaciones mayores, hoy pueden conocer sucesos que están aconteciendo «al otro lado del mundo» en el mismo instante en que ocurren, cuestiones que hace cuarenta años, llegaban como noticias con días o más tiempo de retraso.

De igual forma, el hecho de nacer en un mundo de alta tecnología, implica para las y los más pequeños socializarse desde temprana edad en el uso de los aparatos electrónicos, lo que les otorga un plus, en ese ámbito, respecto de sus mayores.

El refrán antiguo señalaba que «información es poder», sin embargo, la realidad de extensos grupos de jóvenes muestra que, a pesar de tener acceso a información a través del uso de la tecnología, ellos no han mejorado su posición ni sus posibilidades de participar y decidir en nuestras sociedades. Es decir, siguen careciendo de control sobre sus condiciones de vida en lo inmediato y en lo global.

Esta situación tiene que ver con que el acceso a la información en nuestras sociedades; no es un ejercicio libre, sino que es una acción mediada por las capacidades de consumo, lo que implica que las y los jóvenes de sectores empobrecidos y capas medias ven limitado su acceso a esa tecnología que provee de información. Un ejemplo de lo anterior, es que la posesión de computadoras en Chile, está distribuida de manera similar a la desigual distribución de la riqueza: en el $10 \%$ más rico, 7 de cada 10 personas acceden a computadora, mientras que en el $10 \%$ más pobre, sólo 3 de cada 10 lo hacen. Respecto de conexión a internet en el 10\% de mayores ingresos, 5 de cada 10 personas tiene acceso, mientras que en el $10 \%$ más pobre, sólo 1 de cada 10 personas puede conectarse (Mideplan, 2004).

Es decir, las condiciones de posibilidad para el acceso muestran obstáculos y dificultades, lo que nos lleva a actualizar el refrán que «información es poder»; cuando más bien debiera decir: «poseeracceder y usar tecnología de punta es poder».

Este acceso diferenciado según clase social, permite incluso cuestionar planteos de orden teórico que se proponen describir y analizar este fenómeno en el actual contexto social. Marc Prensky (2001) seña- 
la que existirían hoy dos generaciones en torno al tipo de uso de las tecnologías informáticas. Por una parte, los nativos digitales, serían quienes han nacido en los últimos años en un contexto de alto uso de estas tecnologías, por lo que se vincularían con ellas como aparatos que constituyen parte vital en sus vidas. Por otra parte, estarían los inmigrantes digitales, quienes por su mayor edad han debido hacer un esfuerzo por integrar estas tecnologías en sus vidas e incluso existirían quienes no lo han logrado pues están fuera de los circuitos laborales y/o educativos.

Sin embargo, María Isabel Pavez (2008) señala que las distinciones de Prensky no consideran las condiciones de inclusión y exclusión social que son más determinantes que los meros rangos etáreos en contextos como el de nuestro país. Es decir, la edad como dato duro, no es una dimensión significativa en la construcción de una explicación relevante, sino que la posición en la estructura social, la localización territorial de origen, la valoración de la tecnología en el entorno — familia, escuela, trabajo- , son factores de mayor relevancia y peso en las posibles argumentaciones de esta construcción conceptual.

De tal forma, la autora considera el uso de la categoría nativos para quienes, con independencia de la edad, despliegan desde su nacimiento un vínculo de alta relevancia con la tecnología de punta, haciéndola un elemento vital en los distintos campos de su vida. Para los inmigrantes, Pavez propone una distinción interesante, por una parte los inmigrantes incluidos, que son quienes cuentan con las posibilidades de acceder al uso de la tecnología sin haber nacido en un contexto proclive a ello y la incorporan como elemento vital en sus vidas. Es importante considerar que la valoración que este grupo hace de la tecnología computacional, va ascendiendo desde lo desconocido a lo conocido e importante. En un sentido diferente se plantean los inmigrantes excluidos, quienes no cuentan con las condiciones para acceder o que también se plantean no querer hacerlo, entre otras razones, porque lo perciben como un elemento peligroso para el buen despliegue de sus relaciones humanas.

La capacidad de consumir aparece entonces, como una de las condiciones de posibilidad relevante para el acceso y uso de la tecnología de punta en jóvenes. Las facilidades en este proceso inciden positivamente en la valoración que de ella se haga. En la medida que la condición es nativo o inmigrante incluido, la incorporación del uso se tiende a volver un factor de acercamiento al éxito ya señalado. 
Sin embargo, para las y los jóvenes de sectores empobrecidos, este proceso de relación con las tecnologías de punta, está marcado por las tensiones y los esfuerzos por estar dentro, por constituirse en incluido; es una forma de sobrevivir a las dificultades del contexto. Para ello, las estrategias son al menos las siguientes.

i) Uso de tecnologías e identidades mundializadas, prestigio tecnológico. El proceso acelerado de inventiva tecnológica, ha venido acompañado desde las empresas productoras, de un fuerte influjo mediático que ha buscado instalarse como necesidad humana vital. Tan alto ha sido el logro obtenido por los productores en este sentido, que se ha logrado generar la imagen de cierta democratización en el uso de estas tecnologías, en la medida que procesos similares se están viviendo en diversos puntos del mundo al mismo momento.

Estos procesos de instalación se han sostenido también, en la idea-fuerza de que su posesión y uso, otorga un determinado prestigio social propio de quienes se han modernizado y están en la punta de los adelantos tecnológicos. No estarlo, implica quedar fuera de las posibilidades de acceso a trabajo, a educación y a las relaciones humanas. Sin embargo, estas preocupaciones no son las iniciales en las y los jóvenes, quienes declaran que la posesión es hoy un elemento de sobrevivencia de sus imágenes ante el mundo (INJUV, 2007) y, en segundo término, de sus posibilidades de sobrevivencia material.

Estas lógicas de identidades globales —-mundializadas-, asentadas sobre la noción de prestigio como imagen desde el tener, que se pretenden constitutivas del ser, niegan las oportunidades de inclusión a las y los jóvenes empobrecidos. Sus posibilidades de modernizarse son menores, van quedándose atrapados en imágenes de pasado lento, específico y estático.

ii) Uso de tecnologías y comunicación cara a cara. Una imagen construida desde el mundo adulto, señala que las y los jóvenes estarían hoy capturados por el uso de la tecnología, en especial la que se da en el ámbito comunicacional (Sandoval, 2001). Se parte de la premisa de que las y los jóvenes habrían entregado las posibilidades de relación cara a cara, y que solo las reducirían a encuentros esporádicos donde el eje central estaría dado por el vínculo vía internet en el chat, fotolog, facebook, entre otros.

Sin embargo, dicho planteamiento no considera lo que las y los propios jóvenes señalan a este respecto, en que aclaran que el alto uso de la tecnología comunicacional en sus comunicaciones, no reemplaza el vínculo cara a cara, sino que lo adelanta, lo prepara y lo potencia, 
pero en ningún caso lo reemplaza. Podemos construir una analogía respecto de que esta tecnología actual cumple el rol que en su momento tuvo el teléfono en su aparición y posterior masificación, el cual de ninguna manera ha generado desvinculaciones o instrumentalizaciones en las relaciones que en su uso se generan.

Relevante fue el uso de tecnología en el reciente movimiento estudiantil del año 2006, en que los diversos grupos se apoyaron en ella para difundir sus acciones, comunicar sus apuestas y propuestas, para vincularse en el carácter nacional que dicho proceso adquirió (Aguilera, 2006).

Lo anterior, cuestiona la relación mecánica que se hace del uso de tecnología y deshumanización. En el estudio sobre inmigrantes digitales, Pavez (2008) releva el discurso de los inmigrantes excluidos quienes, por opción propia, intentan vincularse lo mínimo posible y cuestionan a quienes sí lo hacen de manera importante. Sin embargo, el fundamento de su discurso es que dicha conectividad generaría deshumanización de por sí. A contracorriente de dicho discurso, encontramos a quienes, como ya señalamos, se ubican desde la valoración de la conectividad y le otorgan a ella una posibilidad de aportar en la humanización de las relaciones, en tanto soporte y apoyo para ellas.

Si siguiéramos este último argumento, el que las relaciones humanas se verían favorecidas por el uso de las tecnologías comunicacionales, nuevamente se nos queda fuera de esa oportunidadposibilidad un grupo importante de jóvenes empobrecidos que no contará con el acceso que la capacidad de consumo otorga. No estamos hablando de un artefacto natural, sino de un producto de la industria tecnológica, transformado en producto de la industria de consumo. Su acceso entonces, estará mediado por las capacidades de compra y/o endeudamiento de cada sujeto.

Como se observa, una de las ideas-fuerzas con que se ha instalado la tecnología en la cotidianidad social, es que su acceso y uso otorgarían pasaje directo al logro de la felicidad. Tener y usar tecnología es condición para la dicha y el bienestar. Usar tecnologías facilitaría el trabajo, los quehaceres domésticos, la información, la comunicación, entre otros beneficios.

Sin embargo, la percepción de felicidad no aumenta y, más bien, crecen las nociones de mayor urgencia, apuro y exigencia que hace años o décadas atrás (Pavez, 2008). Lejos de disminuir la carga de trabajo, más bien pareciera que hoy se ha aumentado la misma y que el correo electrónico constituye un beneficio comunicacional pero, al 
mismo tiempo, se ha transformado en una exigencia que genera dependencia y malestar.

La felicidad ofrecida en la promoción de estos artefactos no se cumple. El bienestar adherido a su uso no se logra. La modernización tecnológica cumple otros objetivos: prestigio y velocidad del vínculo. Si no se accede a ella o si uso es básico o mínimo, las posibilidades de contar con el estatus modernizado se dificultan y vuelven no posibles. La modernización tecnologizada, en el sentido que hemos explicado, es altamente discriminatoria como proceso social porque genera sobrantes y excluidos. Las luchas por sobrevivir en este campo son permanentes por parte de las y los jóvenes de sectores empobrecidos.

\section{SALIENDO DEL TEXTO}

Como hemos visto, si bien es plausible la posibilidad de éxito a través del consumo opulento, ya sea a través de la compra directa o del crédito como una vía para conseguir ese logro, la inserción laboral que genere los ingresos para esa compra, o la modernización tecnológica como acceso al prestigio exigido, los sectores jóvenes empobrecidos tienden a quedar fuera de dicha posibilidad. Más bien lo que se va generando, son un conjunto de consecuencias que imposibilitan su despliegue, su crecimiento y, lo que en este texto nos interesa, su vinculación a lo social en igualdad de condiciones.

Las estrategias del rebusque en el consumo o del sometimiento acrítico en la producción laboral, o el acceso y uso de la tecnología comunicacional como modo de estar modernizado, permiten un tipo de triunfo que de igual manera carga con sensación de derrota y pérdida, en la medida que impone condiciones que matan en vida, que otorgan fugacidad al éxito obtenido.

La contra cara que pone al sujeto de frente a su realidad cotidiana, es la estabilidad de las carencias. Ellas permanecen, no son fugaces y están reiteradamente interrogando a este sujeto por la calidad de su triunfo, por la sostenibilidad de su éxito. Carencias permanentes, éxitos fugaces, frustraciones y angustias sostenidas, triunfos y valoraciones efímeras.

Desde estos elementos, se abren nuevas interrogantes que cuestionan respecto de las marcas generacionales que este modo de ser y constituirse va a dejar en importantes grupos de nuestras poblaciones empobrecidas. Como nunca antes el consumo - como hemos analizado, directo o indirecto- - y la búsqueda del éxito a través de él, estuvo tan presente en nuestras sociedades. Es en esta época, en que ha gana- 
do un sitial de relevancia el consumir de manera opulenta y ceder ante la fascinación que esa opulencia genera.

Lo anterior puede llevar a la despolitización, a negarse ante la posibilidad de desplegar conductas reñidas con el festín que el mercado ofrece. La acción crítica o reivindicativa, se aparece en este escenario como una tentación pecaminosa que saca del circuito naturalnaturalizado. No se debe ceder a dicha tentación, hay que fortalecerse y emprender. Las posibilidades están dadas.

Sin embargo, a pesar de ese imaginario de un mercado concebido como democrático porque ofrecería todas las posibilidades, existen quienes no aprovechan esa oferta. Existen quienes no se pliegan a la ruta del éxito y de manera incomprensible — para las agencias promotoras del consumo como vía al éxito- se quedan fuera de esta modernización, del progreso y de la novedad. Por una parte, no se educan —capacitación, actualización - para el mundo del trabajo, no se insertan en las condiciones señaladas por ese mercado y no utilizan la tecnología de manera significativa y, por otra, no usan los caminos legitimados para acceder al consumo que este mercado plantea en la sociedad.

Las y los jóvenes de sectores empobrecidos, para esta racionalidad exitosa de mercado, no son considerados en absoluto, como víctimas de los procesos de exclusión social, sino que son concebidos como sus propios victimarios, por no aprovechar las ofertas ya señaladas. Si el mercado instala todas las posibilidades y no son aprovechadas por estos jóvenes, no existe responsabilidad ni en el mercado, ni en la política pública, sino que existe culpa — valoración penalizada de la responsabilidad- en quienes no han sabido utilizar adecuadamente la amplia oferta educacional, de consumo, de trabajo, de tecnología, etc., que son presentadas como «al alcance de la mano».

Este discurso de sacrificio, según Hinkelammert, es propio de las racionalidades occidentales capitalistas que, valiéndose del influjo de la religión católica dominante, recrea imaginarios conservadores en la población, potenciando las construcciones que agudizan la auto culpabilidad y el ensimismamiento como estilos de vida para expiar dichas culpas (Hinkelammert, 1991).

Estos imaginarios sacrificiales, profundizan las consecuencias adversas producidas en la construcción de identidades y relaciones sociales que las y los jóvenes de sectores empobrecidos despliegan. De esta manera, la búsqueda del éxito a través del consumo opulento, la producción eficiente y la modernización tecnológica, ratifican la condición de no ser que muchos de estos jóvenes experimentan. 
Se abre la interrogante por la capacidad de movilización en perspectiva de transformación, que estas situaciones pueden generar en estas poblaciones. Si acaso el no acceso o acceso por rebusque terminen generando tal bronca e irritación por exclusión, que se desarrollen explosiones sociales, o una movilización con horizontes de esperanza. Por ahora, la correlación indica que las identidades que se pretenden exitosas, agenciadas a través del consumo, la eficiencia laboral y la modernización tecnológica, llevan la voz cantante en el festín analizado.

Una interrogante atractiva de indagar en estudios posteriores, hace referencia a la caracterización de las racionalidades que se alojan tras estos modos de relacionarse con el éxito exigido desde los discursos dominantes. Desde ahí podría interrogarse a las propias poblaciones jóvenes por cuáles son las identidades deseables que se plantean en este contexto y su vínculo - subordinado, indiferente, crítico, entre otras posibilidades-, respecto de lo esperado. Una tensión estructural de dicho análisis, es la pregunta por los procesos de mayor envergadura que podrían explicarse desde estos hallazgos, en una suerte de lectura generacional de este ámbito de lo social.

SANTIAGO (CHILE), MARZO 2009

RECIBIDO: ABRIL 2009

ACEPTADO: JUNIO 2009

\section{REFERENCIAS BIBLIOGRÁFICAS}

Aguilera, Oscar (2006): «Movidas, movilizaciones y movimientos. Etnografía al movimiento estudiantil secundario en la quinta región». Revista Observatorio de la Juventud $\mathrm{N}^{\circ} 11$. Santiago: INJUV.

BAUMAN, Zygmunt (1999): La globalización. Consecuencias humanas. Buenos Aires: FCE.

BECK, UlRICK (1998): La sociedad del riesgo. Hacia una nueva modernidad. Barcelona: Paidós.

Bourdieu, PierRe (1990): «La juventud no es más que una palabra». En Sociología y cultura. México: Grijalbo.

CEPAL y OIJ (2004): La juventud en iberoamérica. Tendencias y urgencias. Santiago: CEPAL y OIJ.

COOPER, DORIS. (2005): Delincuencia y desviación juvenil. Santiago: LOM.

CORTÉs, JULIO (2008): «Los adolescentes y las transformaciones actuales del control social punitivo en Chile». En Análisis del año 2007. Santiago: Departamento de Sociología, Universidad de Chile. 
CotTet, PABlo y Ligia Galván (1993): Jóvenes: una conversación social por cambiar. Santiago: ECO.

DÁvila, OsCAR; FELIPE GHIARDO y CARLOS MEdRANo (2005): Los desheredados. Trayectorias de vida y nuevas condiciones juveniles. Viña del Mar: Ediciones CIDPA.

DíAZ, ÁLVARO y JAVIER MARTíNEZ (1995): «Chile: la gran transformación». Documento de Trabajo $\mathrm{N}^{\circ} 148$. Santiago: Ediciones Sur.

DuARTE, Claudio (2001): «¿juventud o juventudes? Versiones, trampas, pistas y ejes para acercarnos progresivamente a los mundos juveniles». En Claudio DuARTE y DANAHÉ ZAMBrano (editores): Acerca de jóvenes, contraculturas y sociedad adultocéntrica. San José de Costa Rica: Departamento Ecuménico de Investigaciones (DEI).

(1997): Participación comunitaria juvenil. Miradas desde las lunas y los soles en sectores populares. Santiago: Instituto de la Mujer.

- (1994): Juventudes populares. El rollo entre ser lo que queremos o ser lo que nos imponen. Santiago: LOM.

— y Figueroa Rodrigo (2005): Análisis de las juventudes en Chile. Preguntando desde la educación y la empleabilidad. Santiago: ChileCalifica, GTZ e Interjoven.

ECHEVERRÍA, CRISTIÁN (1990): «El Estado y la capacitación de jóvenes en Chile». En Los jóvenes en Chile hoy. Santiago: CIDE, CIEPLAN, INCH, PSI, SUR.

FigueroA, Rodrigo (2003): Desempleo y precariedad en la sociedad de mercado. Santiago: Universidad de Chile, PREDES-RIL.

FLORES, FERNANDO y JOHN GRAY (2002): El espíritu emprendedor y la vida wired: el trabajo en el ocaso de las carreras. Londres.

Gallardo, Helio (2006): Siglo XXI. Producir un mundo. San José de Costa Rica: Editorial Arlequín.

GarCía CANClini, NÉSTOR (1990): Culturas híbridas. Estrategias para entrar y salir de la modernidad. Grijalbo. México.

GOFFMAN, IRVING (2003). Estigma. La identidad deteriorada. Buenos Aires: Amorrortu.

HinKelammert, Franz (1991). Sacrificios humanos y sociedad occidental. San José de Costa Rica: DEI.

(1990): Las armas ideológicas de la muerte. San José de Costa Rica: DEI.

INJUV (2007): V encuesta nacional de juventud. Santiago: INJUV.

LARRAín, JoRge (1996): Modernidad, razón e identidad en América Latina. Santiago: Editorial Andrés Bello.

MARCEL, MARIO (1990): «El desempleo juvenil en Chile y los desafíos del gobierno democrático». En Los jóvenes en Chile hoy. Santiago: CIDE, CIEPLAN, INCH, PSI, SUR.

MARCUSE, HERBERT (1973): La protesta Juvenil. Barcelona: Salvat Editores. 
Margulis, Mario y Marcelo UrResti (1996): «Moda y juventud». En La juventud es más que una palabra. Buenos Aires: Editorial Biblos.

MARTíNEZ, JAVIER y ARTURO LEÓN (2001): «La estratificación social chilena hacia fines del siglo XX». Series de la CEPAL. Santiago: CEPAL.

MidePlan (2004): Encuesta Casen 2003. Santiago: Mideplan.

MOUlian, TOMÁs (1999): El consumo me consume. Santiago: LOM.

- (1997): Chile actual. Anatomía de un mito. Santiago: LOM.

MuÑoz, VícTOR (1999): «El tratamiento de la juventud desde una perspectiva histórica. Aspectos conceptuales». Inédito.

OIT (2007): Trabajo decente y juventud. América Latina. Lima: OIT. (2003): Panorama laboral. Lima: OIT.

PAVEZ, MARÍA ISABEL (2008): «Nativos e inmigrantes digitales: caracterización exploratoria de estudiantes universitarios». Tesis de grado de magíster en antropología y desarrollo. Santiago: Universidad de Chile.

PRENSKY, MARC (2001): «Digital natives, digital immigrants».

Disponible en: www.marcprensky.com.

SAlAZAR, GABRIEL y Julio PinTO (2003): Historia contemporánea de Chile $V$. Niñez y juventud. Santiago: LOM.

SANDOVAL, MARIO (2001): Sujetos y actores en una sociedad en cambio. Santiago: Universidad Cardenal Raúl Silva Henríquez.

Weinstein, José (1994): «Los jóvenes y la educación media». En Primer informe nacional de juventud. Santiago: Instituto Nacional de la Juventud. 